\title{
AVULSÃO DENTÁRIA: PROPOSTA DE TRATAMENTO E REVISÃO DA LITERATURA
}

\section{TOOTH AVULSION: PROTOCOL OF TREATMENT AND LITERATURE REVIEW}

\author{
Tânia Lemos Coelho Rodrigues* \\ Fabiano Gonzaga Rodrigues" \\ Julierme Ferreira Rocha"*
}

\begin{abstract}
RESUMO
Introdução: A avulsão dentária consiste no deslocamento do dente para fora do seu alvéolo sendo conduta imperativa o reimplante do dente avulsionado na sua loja óssea. O enfoque do traumatismo dentário como um problema de saúde pública tem se tornado evidente e estudos demonstram a necessidade da difusão do protocolo do reimplante dentário para auxiliar o cirurgião-dentista sobre como conduzir e tratar a avulsão dentária. Este trabalho tem como objetivo apresentar um protocolo para o tratamento do dente avulsionado, bem como fazer uma revisão da literatura acerca da etiologia, prevalência, meios de armazenagem, condutas endodônticas, contraindicações dos reimplantes dentários e prognóstico. Conclusão: Conclui-se que o tratamento conservador da avulsão dentária, através do reimplante dental, é um método com considerável chance de sucesso, desde que um pronto atendimento seja estabelecido de forma adequada.
\end{abstract}

DESCRITORES: Reimplante dentário • Avulsão dentária • Protocolos clínicos • Traumatismos dentários.

\section{ABSTRACT}

Introduction: The tooth avulsion consists on the tooth displacement out of its socket being a mandatory conduct the replantation of the tooth in question into its bone socket. The focus of dental trauma as a public health problem has become evident and studies show the necessity of the dissemination of the dental replantation protocol to assist the surgeon-dentist about how to conduct and treat the tooth avulsion. This paper has as objective to present a protocol to the treatment of tooth avulsion as well as a literature review on the etiology, prevalence, storage means, endodontic conducts, against indications of dental replantation and prognosis. Conclusion: We conclude that the conservative treatment of tooth avulsion through dental replantation is a method with considerable chance of success if there is a prompt care in an adequate manner.

DESCRIPTORS: Tooth replantation • Tooth avulsion • Clinical protocols • Tooth injuries

\footnotetext{
* Professora Doutora de Cirurgia Buco-Maxilo-Facial do Curso de Odontologia da Universidade Federal da Paraíba - UFPB

** Professor Doutor de Cirurgia Buco-Maxilo-Facial do Curso de Odontologia da Universidade Federal da Paraíba - UFPB

*** Mestrando em Estomatologia pela Faculdade de Odontologia de Bauru-Universidade de São Paulo.
} 
RODRIGUES TLC,

RODRIGUES FG,

ROCHA JF.

AVULSÃO DENTÁ-

RIA: PROPOSTA

DE TRATAMENTO

E REVISÃO DA

LITERATURA

\section{8}

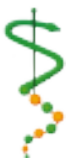

REVISTA DE ODONTOLOGIA DA UNI VERS I DADE CIDADE DE SÃO

PAULO

$2010 ; 22(2): 147-$ 53, MAI-AGO

\section{N T R O D U ÇÃ O}

Nas últimas décadas tem sido mostrado que o traumatismo alvéolo-dentário constitui-se como um fator etiológico responsável pela perda de grande número de dentes. Isso se torna mais crítico quando o pronto atendimento não é conduzido de forma a favorecer a permanência do elemento dentário na cavidade oral.

O traumatismo alvéolo-dentário corresponde a um conjunto de impactos que afeta os dentes e suas estruturas de suporte; por sua vez, a avulsão dentária caracteriza-se pelo total deslocamento do dente para fora do seu alvéolo e, diante de tal situação, recomenda-se o imediato reimplante dental (Andreasen; Andreasen ${ }^{1}$ 2001, Trope et al. ${ }^{2}$ 2002). O reimplante dentário é um tratamento conservador que visa reposicionar o elemento dentário avulsionado no alvéolo dentário, contudo vários fatores devem ser considerados para o sucesso do procedimento.

Muitos profissionais relutam em reimplantar dentes avulsionados, acreditando que se trata de um tratamento temporário, devido à possibilidade do desenvolvimento da reabsorção radicular. Outros, entretanto, não realizam tal procedimento devido ao desconhecimento técnico (Ruiz de Gopegui ${ }^{3}$ 2003, Vasconcelos et al. ${ }^{4} 2001$ ). Soma-se a isso que muitos outros profissionais realizam o protocolo do reimplante dentário de forma inadequada, favorecendo o insucesso da terapêutica. Westphalen et al. ${ }^{5}$ (1999) mostraram que o nível de conhecimento do cirurgião-dentista sobre o procedimento de reimplantar dentes era deficiente e sugeriu um protocolo a fim de orientar a amostra investigada. O estudo desenvolvido por Rocha ${ }^{6}$ (2007) mostra que grande parte dos cirurgiões-dentistas (54\%) já atendeu algum paciente vítima de avulsão dentária. Não obstante, a conduta do protocolo do reimplante foi inadequada.

Assim, a adoção de medidas educativas, tais como palestras e cursos, bem como a elaboração de protocolo-guia, são alternativas viáveis a fim de orientar a classe odontológica e favorecer o sucesso do pronto atendimento ao paciente vítima de avulsão dentária. (Campos et al. ${ }^{7} 2006$;
Poi et al. ${ }^{8}$ 1999, Marzola ${ }^{9}$ 1997, Rocha ${ }^{6}$ 2007, Westphalen et al. ${ }^{5}$ 1999, Trope $^{2}$ 2002).

\section{REVISÃO DA LITERATURA}

Os traumatismos dentários são prevalentes em jovens com idade escolar, tendo como etiologia quedas, quedas de bicicletas, atropelamentos, acidentes automobilísticos, agressões, acidentes motociclísticos e práticas esportivas (Góes et al. ${ }^{10}$ 2005; Prata et al. ${ }^{11}$ 2000). Em relação à faixa etária mais jovem, de 10-19 anos, os fatores etiológicos predominantes foram os acidentes com bicicletas e quedas, e acima dos 20 anos ocorreu maior incidência dos acidentes motociclísticos e automobilísticos.

Dentre as lesões por traumatismo dentário, a avulsão dentária aparece numa prevalência que varia de 0.5 a $16 \%$. A maior incidência das avulsões está associada aos incisivos centrais superiores, em crianças de 7 a 12 anos de idade, em razão das atividades da infância e da adolescência, favorecendo a exposição aos traumas dentais, além da menor quantidade de fibras do ligamento periodontal do dente recém-erupcionado e da rizogênese incompleta (Andreasen; Andreasen ${ }^{1} 2001$, Prata et al. ${ }^{11}$ 2000). A avulsão na dentição decídua ocorre em torno de $0.8 \%$ e o incisivo central superior é o dente mais afetado (Christophersen et al. ${ }^{12}$ 2005).

Gassner et al. ${ }^{13}$ (2004), em análise de 3.385 pacientes, observaram que $76,3 \%$ apresentaram traumatismo alvéolo-dentário, dentre os quais $7,2 \%$ sofreram avulsões. Em estudo realizado por Prata et al. ${ }^{11}$ (2000) foram avaliados os prontuários de 151 pacientes e verificados 264 dentes permanentes traumatizados, sendo que a avulsão dentária foi o tipo de trauma mais frequente com 25,76\% dos casos. Em outro estudo realizado por Siviero et al. ${ }^{14}$ (2005), os resultados mostraram que a avulsão corresponde a $11,64 \%$ dos casos de traumatismos alvéolo-dentários.

A prevalência do traumatismo alvéolodentário com relação ao gênero tem mostrado que os meninos são acometidos de aproximadamente duas vezes mais que as meninas - 30 e $16.1 \%$, respectivamente (Soriano et al..$^{15}$ 2004). Panzarini et al. ${ }^{16}$ 
(2003) observaram uma proporção entre o sexo masculino e o feminino de 3:1 respectivamente, relatando que a maior incidência ocorreu na faixa etária entre 10 e 19 anos.

Crianças do gênero masculino, hiperativas, apresentando overjet superior a $5 \mathrm{~mm}$ e selamento labial inadequado têm uma maior predisposição ao trauma dentário (Lalloo ${ }^{17}$ 2003, Soriano et al. ${ }^{15} 2004$, Traebert et al. ${ }^{18}$ 2004).

Uma vez ocorrida a avulsão dentária, a vitalidade do ligamento periodontal é fator de grande importância para o sucesso do reimplante do dente avulsionado, recomendando-se, diante da impossibilidade do reimplante imediato, que o mesmo seja armazenado em um meio úmido, e nunca em meios secos. (Andreasen; Andreasen ${ }^{1}$ 2001, Ellis III ${ }^{19}$ 2005, Westphalen et al. ${ }^{5}$ 1999).

Vários são os meios citados na literatura para armazenagem do dente avulsionado, dentre eles: Solução Salina Balanceada de Hank`s (SSBH), sangue, saliva, leite, vestíbulo bucal, meios de cultura (Sigalas et al. ${ }^{20}$ 2004).

Em pesquisa de Hiltz e Trope ${ }^{21}$ (1991) mostrou-se que os fibroblastos armazenados no leite permaneceram vitais, porém com alteração da sua morfologia, enquanto que a armazenagem na Solução Salina Balanceada de Hank's não promoveu alterações morfológicas, nem alterou a capacidade mitótica das células. Dessa forma, os autores concluíram que a Solução Salina Balanceada de Hank`s poderia manter $70 \%$ dos fibroblastos vitais por 96 horas. Soares et al. ${ }^{22}$ (2003) corroboram com este estudo.

Se a Solução Salina Balanceada de Hank`s não estiver disponível no local do ferimento, é importante salientar que o leite tem mostrado ser a melhor alternativa, porque sua osmolaridade e pH estão numa escala biológica aceitável (Lee et al. ${ }^{23}$ 2001), podendo armazenar o dente avulsionado por um período de até seis horas. (Blomlöf et al. ${ }^{24}$ 1983)

A saliva por ser um meio contaminado e ligeiramente hipotônico não é um meio recomendado, pois pode favorecer a penetração bacteriana pelas prováveis microfissuras existentes na superfície dentá- ria, permitindo a contaminação bacteriana pulpar, e o estabelecimento da reabsorção radicular externa inflamatória (Yanpiset; Trope $^{25}$ 2000; Westphalen et al. ${ }^{26}$ 2003). A água é a última alternativa, devendo ser utilizada para armazenar dentes avulsionados apenas quando os outros meios citados estão inacessíveis (Trope ${ }^{27} 2000$ ).

Quando um dente é deslocado para fora do seu alvéolo ocorrem danos não só nas fibras periodontais, mas também nos vasos apicais que estão incumbidos de nutrir e oxigenar as células que compõem a estrutura dentária, sendo o dano proporcional à intensidade e duração do trauma dentário ocorrido, estágio de desenvolvimento radicular e possível necrose e infecção dos tecidos envolvidos (Andreasen; Andreasen ${ }^{1}$ 2001).

Normalmente, a cicatrização do processo ocorrerá na seguinte ordem: revascularização do ligamento periodontal rompido, união das fibras de Sharpey rompidas, formação de uma nova adesão gengival e, finalmente, pela revascularização e reinervação da polpa. A revascularização pulpar ocorre na ordem de $0,5 \mathrm{~mm} /$ dia, sendo iniciada quatro dias após o trauma, verificando-se que em torno de 30 a 40 dias a polpa de um incisivo jovem poderá estar revascularizada (Andreasen; Andreasen ${ }^{28}$ 1991).

A necessidade de terapia endodôntica depende do tempo extraoral e do estágio de desenvolvimento radicular (American Association of Endodontics ${ }^{29}$ 2004, Westphalen et al. ${ }^{30}$ 2007). Em dentes com rizogênese completa reimplantados não se pode esperar que ocorra revascularização, e o tratamento endodôntico deverá ser executado 7-10 dias após o traumatismo a fim de impedir novos danos ao ligamento periodontal e/ou o desenvolvimento da reabsorção radicular do tipo inflamatória. Recomenda-se a extirpação pulpar e preenchimento do canal radicular com uma pasta de hidróxido de cálcio (curativo de demora), sendo que a obturação com guta-percha não deverá ser realizada até que uma lâmina dura intacta possa ser detectada radiograficamente (Andreasen; Andreasen ${ }^{1}$ 2001, Trope $^{27}$ 2000).

No caso de dentes avulsionados com rizogênese completa e permanecidos em
RODRIGUES TLC, RODRIGUES FG, ROCHA JF.

AVULSÃO DENTÁ RIA: PROPOSTA DE TRATAMENTO E REVISÃO DA LITERATURA

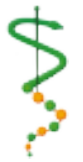

REVISTA DE ODONTOLOGIA DA UN I VERS I DADE Cidade de SÃo PAULO

$2010 ; 22(2): 147-$ 53, MAI-AGO 
RODRIGUES TLC, RODRIGUES FG, ROCHA JF.

AVULSÃO DENTÁRIA: PROPOSTA DE TRATAMENTO E REVISÃO DA LITERATURA

REVISTA DE ODONTOLOGIA DA UNI VERS I DADE CIDADE DE SÃO PAULO 53, MAI-AGO um meio seco extraoral por um período superior a 60 minutos, o tratamento de escolha consiste na remoção do ligamento periodontal e tratamento da superfície radicular por meio de substâncias químicas, antes do reimplante. (Trope ${ }^{2,27}$ 2002, 2000). O tratamento endodôntico extraoral é o adequado, pois o paciente não será submetido a procedimentos adicionais, tais como: radiografias, anestesia, dentre outros.

Em dentes com rizogênese incompleta com período de permanência no meio extraoral inferior a 60 minutos, poderá ocorrer o processo de revascularização pulpar. A imersão em uma solução com doxiciclina ( $1 \mathrm{mg} / 20 \mathrm{ml}$ de soro fisiológico) aplicada topicamente por 5 minutos antes do reimplante favorece esaa revascularização (Yanpiset; Trope ${ }^{25}$ 2000). Todavia, o acompanhamento radiográfico por 3-4 semanas após o traumatismo poderá evidenciar alguma alteração patológica, devendo-se, nesse caso, iniciar o tratamento endodôntico. (Trope ${ }^{2,27}$ 2002, 2000).

A taxa de sucesso do reimplante dentário é em torno de 4 a 5\%, e uma das causas desse baixo índice é o desconhecimento do cirurgião-dentista perante a terapêutica indicada para cada caso individualmente. A filosofia predominante para o tratamento eficaz tem sido reimplantar o dente o mais rápido possível depois da avulsão, de modo que se mantenha a vitalidade das células do ligamento periodontal. Todavia, o prognóstico é totalmente dependente do tempo extraoral, do meio de armazenagem do dente avulsionado, do tipo e do tempo de esplintagem e da terapia endodôntica adequada (Krasner; Rankow ${ }^{31}$ 1995, Westphalen et al. ${ }^{5}$ 1999).

Após o reimplante do dente avulsionado, recomenda-se a estabilização deste através da esplintagem semirrígida com fio de nylon e resina composta ou outro similar, por um período de 7 a 14 dias. Essa contenção favorecerá a cicatrização pulpar e periodontal, bem como a estabilização dentária durante o período de cicatrização. Além disso, deverá ser feita uma análise criteriosa da extensão da esplintagem, pois muitas vezes os dentes adjacentes possuem algum tipo de trauma associado (Schein; Isolan ${ }^{32}$ 1997).

Após o procedimento de reimplante dentário, está indicada a prescrição de antibiótico por um período de 7-10 dias, antiinflamatório por 3 a 5 dias, além da profilaxia antitetânica (Westphalen et al. ${ }^{5}$ 1999). A esplintagem rígida está indicada quando houver fratura do processo alveolar concomitante ao trauma de avulsão dentária, sendo que sua permanência deverá ser de 4-8 semanas (Andreasen; Andreasen ${ }^{1}$ 2001). Uma dieta leve por duas semanas e higienização local com escovas macias e bochechos de clorexidina a $0.12 \%$ durante uma semana são igualmente importantes. (American Association of Endodontics ${ }^{29}$ 2004).

O acompanhamento clínico e radiográfico pelo profissional deverá ser feito por no mínimo 5 anos, iniciando-se semanalmente nos primeiros dois meses,

Tabela 1: Sinais clínicos e radiográficos dos principais tipos de reabsorção radicular que podem ocorrer após o reimplante dentário.

\begin{tabular}{ccc}
$\begin{array}{c}\text { TIPO DE } \\
\text { REABSORÇÃO } \\
\text { RADICULAR }\end{array}$ & SINAIS CLÍNICOS & SINAIS RADIOGRÁFICOS \\
$\begin{array}{c}\text { Reabsorção } \\
\text { Superficial }\end{array}$ & $\begin{array}{c}\text { Ausência de mobilidade, } \\
\text { assintomático; processo auto- } \\
\text { limitante. }\end{array}$ & $\begin{array}{c}\text { Irregularidade ao nível do ápice radicular } \\
\text { e/ou concavidades acompanhando a } \\
\text { superfície lateral da raiz }\end{array}$ \\
$\begin{array}{c}\text { Sensibilidade aos testes de } \\
\text { Reabsorção } \\
\text { Inflamatória }\end{array}$ & $\begin{array}{c}\text { um som abafado; possível } \\
\text { mobilidade dentária. }\end{array}$ & $\begin{array}{c}\text { Reabsorção radicular em forma de tigela. Há } \\
\text { envolvimento ósseo }\end{array}$ \\
$\begin{array}{c}\text { Reabsorção por } \\
\text { Substitutição } \\
\text { (Anquilose) }\end{array}$ & $\begin{array}{c}\text { Dente em infra-oclusão; } \\
\text { som metálico ao teste da } \\
\text { percussão. }\end{array}$ & $\begin{array}{c}\text { Ausência do espaço do ligamento } \\
\text { periodontal e de áreas radiolucentes }\end{array}$ \\
\hline
\end{tabular}


passando-se a semestralmente, e, após o primeiro ano, o controle deverá ser anual. (American Association of Endodontics ${ }^{29}$ 2004).

Esse acompanhamento é importante, pois uma das sequelas mais sérias e frequentes relacionadas ao dente avulsionado é a reabsorção radicular. Classificamse em três tipos diferentes: Reabsorção Superficial, Reabsorção Inflamatória e Reabsorção por Substituição, conforme a Tabela 1.

O prognóstico para dentes com permanência extraoral superior a 60 minutos em meio seco provavelmente será a anquilose. Portanto, para evitá-la recomenda-se a remoção do ligamento periodontal e o tratamento da superfície radicular através da inserção do elemento dentário em uma solução de fluoreto de sódio a $2.4 \%$ e pH de 5.5, por 20 minutos, ou aplicando-se o

Protocolo sugerido após avulsão dentária - Tempo extraoral inferior a 60 minutos Dentes Permanentes

\begin{tabular}{|c|c|}
\hline Dentes permanentes com RIZOGÊNESE CON & Dentes permanentes com RIZOGÊNESE INCOMPLETA \\
\hline $\begin{array}{l}\text { - Irrigue o dente e o alvéolo com soro fisiológico; } \\
\text { - Examine o alvéolo, o elemento dentário e os } \\
\text { tecidos moles adjacentes; } \\
\text { - Reimplante imediatamente, se possível (se não for } \\
\text { possível o reimplante imediato, coloque o dente } \\
\text { em um meio fisiológico: leite ou soro fisiológico) } \\
\text { - Aplique esplinte semi-rígido por 7-14 dias e inicie } \\
\text { a terapia endodôntica em 7-10 dias. } \\
\text { - Administre antibiótico por 7-10 dias; anti-infla- } \\
\text { matório por } 5 \text { dias; analgésico, se necessário. } \\
\text { - Verificar a necessidade de profilaxia antitetânica; } \\
\text { - Controle clínico e radiográfico. }\end{array}$ & $\begin{array}{l}\text { - Irrigue o dente e o alvéolo com soro fisiológico; } \\
\text { - Examine o alvéolo, o elemento dentário e os } \\
\text { tecidos moles adjacentes; } \\
\text { - Reimplante imediato; } \\
\text { - Poderá ocorrer a revascularização pulpar (oblite- } \\
\text { ração da câmara pulpar e progressão do desen- } \\
\text { volvimento radicular); } \\
\text { - Há alterações patológicas, inicie a apexificação; } \\
\text { - Aplique esplinte semi-rígido por 7-14 dias; } \\
\text { - Administre antibiótico por 7-10 dias; anti-infla- } \\
\text { matório por } 5 \text { dias; analgésico, se necessário. } \\
\text { - Verificar a necessidade de profilaxia antitetânica; } \\
\text { - Controle clínico e radiográfico. }\end{array}$ \\
\hline
\end{tabular}

Protocolo sugerido após avulsão dentária - Tempo extraoral superior a 60 minutos Dentes Permanentes

Dentes permanentes com RIZOGÊNESE COMPLETA

Dentes permanentes com RIZOGÊNESE INCOMPLETA

Se decidir reimplantar, observar a sequência:

- Irrigue o dente e o alvéolo com soro fisiológico;

- Examine o alvéolo, o elemento dentário e os tecidos moles adjacentes;

- Antes do reimplante, remova o ligamento periodontal e inicie a terapia endodôntica;

- Aplique NaF 2.4\% e pH 5.5, por no mínimo 5 minutos na superfície radicular;

- Reimplante o dente avulsionado;

- Esplinte semi-rígido por 7-14 dias;

- Administre antibiótico por 7-10 dias; anti-inflamatório por 5 dias; analgésico, se necessário.

- Verificar a necessidade de profilaxia antitetânica; - Controle clínico e radiográfico.
Emdogain $\AA$, uma matriz derivada do esmalte que possui proteínas da família das amelogeninas para retardar o processo de reabsorção radicular externa por substituição. (Lee et al. ${ }^{23}$ 2001; Andreasen, Andreasen $^{1}$ 2001; Ashkenazi e Shaked ${ }^{33}$ 2006).

\section{CONS IDERAÇÕES FINAIS}

$\mathrm{O}$ ato de reimplantar dentes avulsionados consiste em um tratamento conservador e de baixo custo, sendo a confecção de manuais e fôlderes um método adequado para orientar de forma clara e efetiva não só o Cirurgião-dentista a conduzir e tratar de forma ideal os casos de avulsão dentária, mas também a população leiga e a comunidade, possibilitando ao paciente portador desse tipo de trauma um pronto atendimento adequado com maior possibilidade de sucesso.
-Reimplante não é indicado.

-Reimplante não é indicado.

RODRIGUES TLC, RODRIGUES FG, ROCHA JF.

AVULSÃO DENTÁRIA: PROPOSTA DE TRATAMENTO E REVISÃO DA LITERATURA

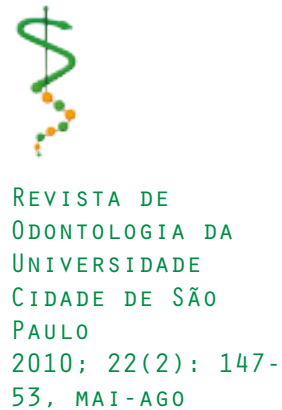


RODRIGUES TLC,

RODRIGUES FG,

ROCHA JF.

AVULSÃO DENTÁ-

RIA: PROPOSTA

DE TRATAMENTO

E REVISÃO DA LITERATURA

REVISTA DE

ODONTOLOGIA DA UNIVERSIDADE

CIDADE DE SÃO:

PAULO

$2010 ; 22(2): 147-$

53, MAI-AGO

\section{REFERÊNCIAS:}

1. Andreasen JO, Andreasen, FM. Texto e atlas colorido de traumatismo dental. $3^{\mathrm{a}}$ ed. Porto Alegre: Artmed; 2001.

2. Trope M. Clinical management of the avulsed tooth: present strategies and future directions. Dental Traumatology. 2002 Feb; 18(1): 1-11.

3. Ruiz de Gopegui FJ. Incisivo central permanente avulsionado. Conducta y caso clínico. RCOE. 2003 jul-ago; 8(4): 429-437.

4. Vasconcelos BCE, Fernandes BC, Aguiar ERB. Reimplante dental. Rev Cir Traumat Buco -Maxilo-Facia. 2001 jul-dez; 1(2): 45-51.

5. Westphalen VPD, Barussot A, Guarianti R, et al. Avulsão dentária: condutas clínicas. JBC- J Bras Clin Estét Odont 1999;3(15):79-83.

6. Rocha JF. Nível de conhecimento do cirurgião-dentista atuante na cidade de João Pessoa acerca da avulsão dentária. [Monografia]. João Pessoa: Universidade Federal da Paraíba; 2007.

7. Campos MI da C, Henriques KAM, Campos CN. Nível de informação sobre a conduta de urgência frente ao traumatismo dental. Pesq Bras Odontoped Clin Integr 2006 mai-ago; 6 (2): 155-159.

8. Poi WR, Poi WE, Salineiro SL, Miziara FV et al. A educação como forma de favorecer o prognóstico do reimplante dental. Rev da APCD São Paulo 1999 nov-dez; 53 (6): 474-479.

9. Marzola C. A reimplantação dental. In: São Paulo: Pancast. 1997, p.289-357.

10. Góes KKH de, Ribeiro ED, Lima Júnior JL, et al. Avaliando os traumatismos dentoalveolares: revisão de literatura. Rev. Cir. Traumatol. Buco-Maxilo-Fac, Camaragibe. 2005 jan-mar; 5(1): 21-6.

11. Prata THC, Duarte MSR, Miquilito JL et al. Etiologia e freqüência das injúrias dentárias traumáticas em pacientes do centro de traumatismos dentários da Faculdade de Odontologia de São José dos Campos - Unesp. Rev Odontol Unesp São Paulo. 2000 jan-dez; 29 (1/2): 43-53.

12. Christophersen P, Freund M, Harild L. Avulsion of primary teeth and sequelae on permanent successors. Dent Traumatology. 2005 Dec; 21(6): 320-3.

13. Gassner R, Tuli T, Hãchl O et al. Craniomaxillofacial trauma in children: a review of 3.385 cases with 6.060 injuries in 10 years. J Oral Maxillofac Surg, Philadelphia. 2004 Apr; 62(4): 399-407.

14. Siviero AC, Westphalen VPD, Deonizio MDA. Prevalência de avulsões dentárias no Pronto-Socorro Odontológico do Hospital Cajuru. Rev de Clín Pesq Odontol 2005 jan-mar;1 (3): 48-50.

15. Soriano EP, Caldas Jr AF, Góes PSA. Risk factors related to traumatic dental injuries in Brazilian schoolchildren. Dent Traumatology. 2004 Oct; 20(5): 246-50.

16. Panzarini SR, Saad Neto M, Sonada CK et al. Avulsões dentárias em pacientes jovens e adultos na região de Araçatuba. Rev da APCD São Paulo 2003 jan-fev; 57 (1): 27-31.

17. Lalloo R. Risk factors for major injuries to the face and teeth. Dent Traumatology. 2003 Feb; 19(1): 12-4. 
18. Traebert J, Almeida ICS, Gargheti C, et al. Prevalência, necessidade de tratamento e fatores predisponentes do traumatismo na dentição permanente de 11 a 13 anos de idade. Cad. Saúde Pública Rio de Janeiro 2004 mar-apr; 20 (2): 403-10.

19. Ellis III E. Traumatismo dentoalveolar e aos tecidos moles. In: Peterson LJ et al. Cirurgia Oral e MaxiloFacial Contemporânea. $4^{\mathrm{a}}$ ed. Rio de Janeiro: Elsevier; 2005. p. 535-558.

20. Sigalas E, Regan JO, Kramer PR et al. Survival of human periodontal ligament cells in media proposed for transport of avulsed teeth. Dent Traumatology 2004 Fev; 20: 21-8.

21. Hiltz J, Trope M. Vitality of human lip fibroblasts in milk, Hank's balanced salt solution and ViaSpan storage media. Endod Dent Traumatol. 1991 Apr; 7(2): 69-72.

22. Soares A, Nishiyama CK, Propowitsch I. Avaliação da preservaçãodo ligamento periodontal em diferentes meios de conservação. Rev da APCD, 2003 mar-abr; 57(2)): 95-100.

23. Lee JY, Vann Júnior WF, Sigurdsson A. Management of avulsed permanent incisors: a decision analysis based on changing concepts. American Academy of Pediatric Dentistry - Pediatric Dentistry 2001 Jul-Aug; 23(3): 357-360.

24. Blomlöf L, Lindskog S, Anderson L, et al. Storage of experimentally avulsed teeth in milk prior to replantation. J Dent Res 1983 Aug; 62(8): 912-6.

25. Yanpiset K, Trope M. Pulp revascularization of replanted immature dog teeth after different treatment methods. Endod Dent Traumatol 2000 Oct; 16(5):211-7. 29. American Association of Endodontics. Treatment of the avulsed permanent tooth: Recommended guidelines of the American Association of Endodontists. AAE publication; p. 1-6, 2004. Disponível em: <http://www.aae.org/dentalpro/guidelines. htm>. Acesso em 30/04/2007 ás 19:28.

26. Westphalen VPD, Moraes IG, Westphalen FH. Reabsorção radicular: mecanismo e classificação. Rev. Odonto Ciênc 2003 jul-set; 18(41): 253-9.

27. Trope M. Treatment of the avulsed tooth. Pediatric Dent 2000 Mar-Apr; 22(2): 145-7.

28. Andreasen JO, Andreasen FM. Avulsão dentária. In: Soluções Clínicas. São Paulo: Panamericana, 1991, p.113-132.

31. Krasner P, Rankow H. A new philosophy for the treatment of avulsed teeth. Oral Surg Oral Med Oral Pathol Oral Radiol Endod. 1995; 79: 616-623.

30. Westphalen, VPD et al. Knowledge of general practitioners dentists about the emergency management of dental avulsion in Curitiba, Brazil. Dental Traumatology 2007 Fev; 23(1): 6-8.

32. Schein MT, Isolan TMP. Esplinte funcional de dentes traumatizados. RBO1997 julago; 54(4): 225-227.

33. Ashkenazi M, Shaked I. In vitro clonogenic capacity of periodontal ligament fibroblasts cultured with Emdogain®. Dent Traumatology 2006 Dec; 22(1): 25-9.

Recebido em 07/05/2009

Aceito em 01/10/2009.
RODRIGUES TLC RODRIGUES FG, ROCHA JF.

avulsão dentá. RIA: PROPOSTA DE TRATAMENTO e REVISÃo Da LITERATURA

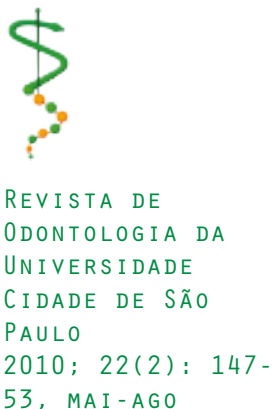

